may occur and may prove fatal. Moreover at these fast rates an impulse may enter the ventricle during the vulnerable phase of the previous repolarization (the apex or nadir of the $T$ wave) and in some circumstances trigger ventricular fibrillation. ${ }^{14}$ The occurrence of atrial fibrillation may be prevented by beta-blocking drugs and quinidine or by procainamide, but this last drug has a high incidence of toxic side effects with long-term use. ${ }^{15}$ Amiodarone (not yet available in Britain) has also proved particularly useful but it carries a risk of corneal damage. Digitalis is contraindicated in susceptible patients because of its effect on the refractory period of the bypass. ${ }^{12}$

Drug therapy does not provide adequate relief for a small minority of patients in whom disabling or life-threatening tachycardias may continue despite the best efforts of physician or cardiologist. Surgical treatment may now be considered in these circumstances. Circus movements may be prevented by the division either of the normal conducting pathways or of the accessory bridge. The former is technically less difficult, partly because the surgeon is dealing with an accessible structure the anatomy of which is well understood, but the two approaches were described almost simultaneously.

Dreifus et al..$^{16}$ reported the successful abolition of refractory paroxysmal tachycardia by the division of the bundle of His; a permanent pacemaker was required because the alternative accessory pathway linking the atrium and the ventricle conducted only intermittently. This procedure may fail to protect patients against the very rapid ventricular response to atrial fibrillation if impulses are transmitted over a bypass tract, but when stimulation studies show that the refractory period of the bypass is not unduly short (and a very rapid ventricular response to atrial fibrillation or flutter therefore impossible) satisfactory results can be achieved.

The accessory bridge cannot be defined by simple inspection of the heart, but in some cases its site can be inferred by accurately timing the onset of activation on the exposed epicardial surface. Epicardial mapping was shown to be feasible in 1967 by groups in Holland ${ }^{6}$ and in America ${ }^{17}$ for patients with the type $B$ abnormaltiy, but the technique requires considerable expertise. This major advance in the electrophysiology of the heart enabled Cobb and others ${ }^{18}$ to divide the atrioventricular ring at the area of anomalous excitation in a patient with W-P-W syrdrome (type B) and so to achieve the first surgical cure: both the abnormal QRS complexes and the episodes of tachycardia were abolished. The successful operative treatment of patients with left ventricular pre-excitation, manifested by Type A W-P-W syndrome has recently been reported, ${ }^{419}$ thus widening the possible indications for surgery in pre-excitation.

Surgical treatment of W-P-W syndrome is still in an early experimental phase and is restricted to a few centres specializing in advanced electrophysiological techniques. Formidable problems remain. Some patients have more than one accessory pathway, ${ }^{7}$ or a single pathway may be inaccessible to the surgeon. The delineation of the bypass may be impossible, even with a combination of intracardiac recordings and epicardial mapping, because of its site or because the conditions of surgery may diminish the reliability of the techniques which are used. Some attempts at mapping have been frustrated by return to normal conduction under anaesthesia. ${ }^{4}$ Re-entry may occur within the A-V node itself, independently of the bypass, section of which would then be unhelpful. ${ }^{20}$ Future developments will be awaited with interest, but even now at least some patients who are incapacitated by tachyarrhythmias can be restored by surgery to a full and healthy life.
1 Wolff, L., Parkinson, J., and White, P. D., American Heart fournal, 1930, 5,685 .

Holzmann, M., and Scherf, D., Zeitschrift für Klinische Medizin, 1932, 121,404

3 Wood, F. C., Wolferth, C. C., and Geckeler, G. D., American Heart Fournal, 1943, 25, 454.

4 Wellens, H. J. J., et al., American Heart fournal, 1974, 88, 69

5 Rosenbaum, F. F., et al., American Heart fournal, 1945, 29, 281.

6 Durrer, D., and Roos, J. P., Circulation, 1967, 35, 15.

7 Josephson, M. E., Caracta, A. R., and Lau, S. H., American Heart fournal, $1974,87,363$.

8 Wolf, L., and Richman, J. L., American Heart Fournal, 1953, 45, 545.

9 Hiss, R. G., and Lamb, L. E., Circulation, 1962, 25, 947.

10 Lown, B., Ganong, W. F., and Levine, S. A., Circulation, 1952, 5, 693.

11 Durrer, D., Schuilenburg, R. M., and Wellens, H. J. J., American fournal of Cardiology, 1970, 25, 690.

12 Wellens, H. J., and Durrer, D., Circulation, 1973, 47, 1229.

13 Krikler, D. M., and Spurrell, R. A. J., Postgraduate Medical fournal, 1974, $50,447$.

14 Dreifus, L. S., et al., Circulation, 1971, 43, 520.

15 Kosowsky, B. D., et al., Circulation, 1973, 47, 1204

16 Dreifus, L. S., et al., Circulation, 1968, 38, 1030.

17 Burchell, H. B., et al., Circulation, 1967, 36, 663 .

18 Cobb, F. R., et al., Circulation, 1968, 38, 1018.

19 Wallace, A. G., et al., Circulation, 1974, 49, 206.

20 Spurrell, R. A. J., Krikler, D., and Sowton, E., British Heart Fournul, $1973,35,113$.

\section{Medical Nemesis}

Nowadays management consultants encourage their clients to solve their problems by "wild thinking"-examining remote and even apparently ludicrous alternatives. From his writings, some people might conclude that the contemporary philosopher Ivan Illich has rejected the traditional Aristotelian method in place of this new technique for arriving at the truth. Present-day society, Illich believes, is sick, largely owing to its waste of resources and the "institutionalization" of many important human activities. Transport based on anything more advanced than a bicycle is bound to exploit other people, in proportion to the vehicle's complexity. Education is maintained largely for the self-interest of the educators: most things useful in adult life are learned outside school, which should be abolished in favour of learning from family, friends, and skilled laymen and later on at work.

Illich has now turned his attention to medicine, and his book Medical Nemesis, published next week, ${ }^{1}$ will disappoint few who had looked forward to the author's rigorous approach being applied to medicine. The medical establishment, Illich believes, has now become a major threat to health. The clinical damage it causes outweighs any potential benefits; medical practice sponsors sickness by reinforcing a morbid society; and the medical profession tends to expropriate the power of the individual to heal himself, removing the "integral experience of pain, sickness, and death."

It might seem easy to dismiss Illich's new onslaught as yet another ignorant tilt at the medical windmills, much like Shaw's Doctor's Dilemma-though, alas, Illich's English style lacks G.B.S.'s sparkle. As our three invited reviewers (p. 573) point out, much of his thesis is based largely on practice in wealthy. North America, and ignores the European tradition, which is often still community-centred and based on selftreatment rather than professional care. Few will recognize medicine as the unmoving monolithic structure he depicts: doctors must be one of the most self-critical professions, constantly examining and challenging traditional beliefs. Recent changes arising from the discussions on medical ethics and audit, paramedical workers, and care for the dying are just four examples of how quickly the profession does adopt new attitudes. And few, having read of the horrors of deathbed scenes in nineteenth century letters and fiction (including Tolstoy's own Ivan Ilyitch ${ }^{2}$ ), could agree that death then was 
a calm, natural event, which has since been subjected to "medicalization," robbing the modern individual of dignity at the end of his life.

Yet Illich's book is both timely and valuable for its indirect effect: many of his points should make doctors pause and think about the role of medicine and where it is going. He is right to point out that in the nineteenth century the introduction of piped water and sanitation did more for public health than medicine: today most doctors would agree that measures such as fluoridation together with the total abolition of cigarette smoking and of true poverty would be more costeffective than much of our sophisticated hospital-based medicine. Medical Nemesis is also published at a time when every nation in the world is beginning to review its priorities, agreeing with Enoch Powell's thesis that unlimited demand is self-defeating. ${ }^{3}$ Indeed, some have suggested that if the present trend continues several countries could well soon be spending no less than $25 \%$ of their gross national product on health. ${ }^{4}$ Today, whatever the politicians may say, in Britainand many other countries-medical resources are rationed ${ }^{5}$ : ". . . the Radcliffe will be forced to continue to choose between its patients. Reluctantly it has chosen neglect for those with non-lethal surgical conditions. . . the remainder are all patients with priority emergencies or needing urgent preventive treatment, and ... there will not be room for them all."”

Instead of concentrating all their attention on trying to obtain further vast resources, therefore, medical men everywhere are going to have to determine priorities, and in a much broader context than previously. A good start has already been made in some countries, with the recent shift to an emphasis on community care and on medical audit. But, as the recent B.M.F. Winchester conference was told, ${ }^{6}$ one drawback to the sort of debate needed to determine priorities is the lack of informed public opinion. Where it exists, public opinion is largely a matter of small pressure groups paying little heed to overall strategies or needs. The recent debate on breastcancer screening well illustrated this point, with numerous statements on the need for such a service in press and Parliament. Yet the inescapable fact emerged clearly only in a recent educational television programme: that national large-scale breast-cancer screening would involve the work of a third of all our surgeons doing nothing else all the time. ${ }^{7}$ Would public debates on subjects such as education and defence be conducted on a similarly uninformed basis ? Is it possible, as Mr. Rudolf Klein alleges, ${ }^{8}$ that medicine suffers from too little attention by the informed outsider rather than too much ? Should doctors play a more active part in putting the issues clearly before the public and then engaging it in professional debates on priorities?

If Canada can be taken as an example, ${ }^{9}$ there are three readily identifiable phases in the evolution of medical care in an advanced country: the provision of free or cheap health care; the concentration on developing teaching hospitals and medical schools; and the organization and rationalization of health services. Many countries are now in this last phase, but many will be on the brink of a fourth. The nature of this is not yet clear and may well vary according to the individual country. Dr. John Evans, for Canada, has argued that the fourth phase may be an active programme of health education, concentrating on adjusting the individual's habits to make him avoid the factors known to predispose towards serious disease. Nevertheless, experience in Britain and elsewhere with campaigns against obesity and smoking and in favour of wearing seat belts-to mention three undisputed factors where the responsibility lies with the individual-does not raise any optimism that such a programme would succeed, even if some would argue that really determined campaigns have not yet been mounted. Nor is it likely that a return to a WilliamMorris-like society, based on simple crafts and skills, that Illich would seem to be advocating, would be any more feasible.

More probably, soon each country will agree how much of its resources should go into health. It will then determine, and go on determining, its own priorities-almost certainly using agreed systems of medical audit and computers. Probably two factors will characterize any such programme: it will not be afraid of relinquishing traditional practices if these are shown to be useless; and it will be more socially oriented than much of present-day health care. If such is the case, then Illich is no Nemesis, but rather Tiresias, the Theban whom Zeus granted the gift of inner prophecy. Doctors should read his book, be irritated, and start thinking about priorities.

1 Illich, I., Medical Nemesis. London, Calder and Boyars, 1974, price $£ 1 \cdot 25$ 2 Tolstoy, L., The Death of Ivan Ilyitch, trans. Constance Garnett. London, Heinemann, 1902.

3 Powell, J. E., Medicine and Politics. London, Pitman Medical, 1966

4 Ophenheimer, C., The Times, 11 November 1974, p. 16

5 Maxwell, R. J., McKinsey Quarterly, Spring 1974, p. 2.

- British Medical fournal, 1974, 4, 272, 327, 389

7 McKeown, T., in On The National Health. B.B.C.2, 18 November 1974.

8 Klein, R., British Medical fournal, 1974, 4, 328.

Evans, J., cited by A. R. Somers, New England fournal of Medicine, 1974, 291, 415.

\section{Assessment and Management of Acromegaly}

The well-known clinical appearance of the patient with established acromegaly results from marked skeletal overgrowth and increase in soft tissue mass. A number of features are the indirect result of an increased growth hormone (G.H.) level; these include osteoarthrosis, increased sweating and sebum secretion, acne, and clinical or chemical diabetes. Hypertension and heart failure secondary to it or to associated ischaemic heart disease or acromegalic cardiomyopathy are common. Endocrine and non-endocrine features (particularly headache and visual field impairment) may occur as a result of the associated pituitary tumour. Life expectancy is reduced as a result of increased mortality from cardiovascular disease in men, cerebrovascular disease in women, and respiratory disease in both sexes. ${ }^{1}$ The mortality rate is lowered when treatment is given, so it is important to identify patients as early as possible.

The development of sensitive and specific assays for G.H. has made it possible to establish (or refute) a diagnosis of acromegaly with certainty even in the early stages of the disease. The diagnosis rests on the demonstration of a raised G.H. level which fails to fall during a two-and-a-half hour oral glucose tolerance test. ${ }^{23}$ The tissue effects of excess G.H. secretion may be assessed objectively by measuring heel pad or skin thickness radiologically or by measuring hand volume -tests which are also of value in assessing the biochemical and clinical response to treatment. There may be impaired carbohydrate tolerance, an increase in serum phosphate, and occasionally hypercalcaemia, but these abnormalities are non-specific.

Pretreatment assessment must include investigation to establish the endocrine effects and anatomical extent of the pituitary tumour, and these findings play a part in planning therapy. Lateral radiographs of the skull show abnormalities 